\title{
Data, Information, Results, Discussion, Hypothesis, and Theory
}

\author{
Marvin L. Birnbaum, MD, PhD
}

Language is the only instrument of science, and words are the signs of ideas.

Samuel Johnson, Preface to

Dictionary

Science starts with ideas. Ideas cannot exist without language, and language is made of words. Language affects what we write, where we put what we write, and what we expect when we read our literature. Unfortunately, few of us ever have been trained in the proper use of our language as it pertains to the reporting of our research activities to our colleagues, either in the written word or when we must present the material to our colleagues. Misuse of certain words pervades our literature, and it seems that it matters not whether the author is a young novice or a seasoned veteran researcher. Further, the misuse of important terms is not confined to the English language, but pervades no matter what the language or even the discipline. Disaster and Emergency Medicine always is multidisciplinary: we cannot practice in a vacuum surrounded only by our medical colleagues. We must arrive at definitions that we all can agree upon, or we have difficulty communicating. Let me start with a few basic definitions.

Perhaps, the most common misuse of terms that I encounter in my role as Editor is the confusion between the words, "data" and "information". For the most part, these terms tend to be used interchangeably.

First, for clarification, data is a pleural term; its singular form is "datum". Therefore, it is not proper to say, "The data is ....", "The data shows ...." "This data....", or even, "The data stinks!" A datum is a thing known or granted; an assumption or premise from which inferences may be drawn. ${ }^{1}$ Data ARE what we gather during our research efforts, whether the techniques used for its accumulation are quantitative or qualitative. The data elements also may be quantitative (numbers) or may be qualitative (non-numerical). Data are part of the results of a project and should be provided in the Results section of a scientific paper. A result is a consequence, issue, or outcome of something; a quantity, formula, etc. obtained by calculation. ${ }^{2}$ It is important that we keep the right stuff in the Results and Discussion sections of our papers.

Important inference may be made from the latter part of the definition of datum and is a clue to its meaning in the context of our scientific work. We build information from the data we acquire. To inform means to tell or impart a quality to, give shape to, or to fashion. It is derived from the Latin, informare. ${ }^{3}$ Thus, information is knowledge gained from the analyses of data; it tells us what the data mean to the person doing the analysis. Given the data, we may or may not agree with the information others derive from the data. The Discussion component of a printed scientific paper is where the information derived from the research data should appear. A discussion is an examination by argument. ${ }^{4}$

Since everyone may not agree with the researchers' synthesis and interpretation of the data, it is important that the data obtained be provided in the Results section of a scientific paper. Thus, we can come to our own conclusions based upon the data provided. Our perceptions of what the data show are colored by our backgrounds, experience, and knowledge, and we may or may not agree with the author's interpretation. A paper stands on the data presented and not on the arguments provided by the author(s). However, the authors should use the Discussion Section to convince us that their interpretation is correct based on their knowledge, research, and synthesis. It is not cogent to include any elements of the Discussion in abstracts or summaries of the research presented. We all have seen or even been party to papers in which we believe the conclusions are not supported adequately by the data provided. This one factor probably results in more rejections of papers for publication than does any other factor. In other words, we do not believe the information provided.

Lastly, there are differences between a hypothesis and a theory. A hypothesis is a proposition made as a basis for reasoning without an assumption of its truth..$^{5}$ As such, it is a supposition made from known facts as a starting point for further investigation. It is derived from the Latin, bupothesis, which means a foundation. On the other hand, a theory is a supposition or system of ideas explaining something, especially one based on general principles independent of particular things to be explained. ${ }^{6}$ Thus, a theory is speculative. It is a sphere of abstract knowledge or speculative thought. Theory is derived from the Greek, theöria, which means a spectator or to look at. Scientifically, proof of a hypothesis supports the hypothesis as a fact. Theories are the end-result of analyses of qualitative data. From such theories, we may derive hypotheses, and then, we attempt to prove or disprove these hypotheses. Theories generally are much broader than are hypotheses. Most believe that the use of quantitative data and inferential statistics are necessary to prove hypotheses. Some believe that multiple studies that come 
to the same theory ultimately are accepted as fact. We accept repeated demonstrations of the same phenomena using qualitative techniques also as fact. Either way, sometimes what we accept as fact now, may be shown later not to be so, as newer data begin to provide us with more information.

Keeping these terms straight and using them properly will facilitate our ability to design better scientific research, to enhance our presentations at meetings and in conferences with our colleagues, and to write better scientific papers based on the information we derive from such studies.
Confusion about what goes where and why is a reason to have your paper returned for at least a "major revision" or even as "rejected". Show your data and convince us that what you say is fact.

Furthermore, at this stage in the development of our science, we are heavily dependent on our relationships with our sister disciplines. Our ability to communicate with our sister disciplines also depends upon our proper use of the language we use. After all, "Every language is a temple, in which the soul of those who speak it is enshrined."

Language is the memory of the buman race. It is a thread or nerve of life running through all ages, connecting them into one common, prolonged, and advancing existence.

William Smith, Thorndale

\section{References}

1. Thompson D (ed): The Concise Oxford Dictionary of Current English (9th ed). Clarendon Press: Oxford, 1995. p. 341.

2. Ibid, 1175 .

3. Ibid, 698 .

4. Ibid, 386 .

5. Ibid, 670 .

6. Ibid, 1446 .

7. Oliver Wendell Holmes, The Professor at Breakfast

\section{Editor's Note:}

There are several new developments since the last issue:

1. You will note that there are several changes in the format of this issue. Based on feedback from our readers, the layout of the printed matter is changing. The first of the changes can be noted in the format of the first page of each article. For easier reading, the abstracts have been extended over two columns and the italics have been removed. Second, the margins have been reduced and the gutters between the pages have been increased.

2. Additional changes in design will be made beginning in the 3 rd issue of this volume. You will notice a different format and different type faces of the Table of Contents and of the Titles and author credits. We believe that this will enhance the appearance of the journal. The exact format will be chosen by the Editorial Board during its meeting at the 12 th World Congress for Disaster and Emergency Medicine in Lyon, France in May of this year.

3. A new section in the Web version of the Journal is planned. A combined bibliography from the references of all of the articles published in PDM will be available with its own search engine for easier access to the relevant literature. When possible, appropriate links to the sources of the references will be added. This should facilitate the easy identification of relevant literature in our field. Shortly, each of these references will be catalogued according to their content.

Your input relative to these changes and your suggestions to help us improve the value of this publication as always, are much appreciated. Enjoy! 